\title{
Threat of Technological Unemployment: Are Hiring Managers Discounted for Using Standardized Employee Selection Practices?
}

\author{
Kevin P. Nolan \\ Hofstra University \\ Nathan T. Carter \\ University of Georgia \\ Dev K. Dalal \\ University at Albany, State University of New York
}

Follow this and additional works at: https://scholarworks.bgsu.edu/pad

Part of the Human Resources Management Commons, Industrial and Organizational Psychology Commons, and the Other Psychology Commons

How does access to this work benefit you? Let us know!

\section{Recommended Citation}

Nolan, Kevin P.; Carter, Nathan T.; and Dalal, Dev K. (2016) "Threat of Technological Unemployment: Are Hiring Managers Discounted for Using Standardized Employee Selection Practices?," Personnel Assessment and Decisions: Number 2 : Iss. 1 , Article 4.

DOI: https://doi.org/10.25035/pad.2016.004

Available at: https://scholarworks.bgsu.edu/pad/vol2/iss1/4

This Main Article is brought to you for free and open access by the Journals at ScholarWorks@BGSU. It has been accepted for inclusion in Personnel Assessment and Decisions by an authorized editor of ScholarWorks@BGSU. 


\title{
Threat of Technological Unemployment: Are Hiring Managers Discounted for Using Standardized Employee Selection Practices?
}

\author{
Kevin P. Nolan ${ }^{1}$, Nathan T. Carter ${ }^{2}$, and Dev K. Dalal ${ }^{3}$ \\ 1. Hofstra University \\ 2. University of Georgia \\ 3. University at Albany, State University of New York
}

\section{KEYWORDS}

employee selection, attribution theory, discounting principle, evidencebased decision making, decision aids, technological unemployment

\begin{abstract}
Two studies were conducted to examine the tenability of Meehl's (1986) "threat of technological unemployment" explanation for why practitioners of employee selection resist using standardized decision-making practices. The results of Study 1 support the existence of this threat by demonstrating that practitioners received less credit for the outcomes of employment decisions when structured rather than unstructured interviews were used to evaluate candidates and analytical rather than holistic data combination was used to determine candidates' overall evaluations. The results of Study 2 support the influence of this threat on employee selection by demonstrating that practitioners recognized the effects using the standardized practices have on stakeholders' perceptions of their causality/control over the hiring process and that practitioners' beliefs about stakeholders' perceptions of their causality/control over the hiring process significantly influenced their intentions to use the employee selection practices via concerns about the perceived value of their employment (i.e., fear of technological unemployment).
\end{abstract}

Research strongly supports the use of standardized decision-making practices for employee selection (Highhouse \& Kostek, 2010; Schmidt \& Hunter, 1998; Wollowick \& McNamara, 1969). Practitioners, nevertheless, continue to rely on unstructured and intuition-based approaches to hiring (Ryan, McFarland, Baron, \& Page, 1999; Simola, Tagger, \& Smith, 2007; van der Zee, Bakker, \& Bakker, 2002). The lack of standardization that characterizes these approaches compromises the reliability and predictive validity of employee selection systems (Conway, Jako, \& Goodman, 1995; Huffcutt \& Arthur, 1994) and exposes the hiring process to the idiosyncratic beliefs and biases of decision makers (Arthur, Bell, Villado, \& Doverspike, 2006; Judge, Higgins, \& Cable, 2000). Identifying the factors that underlie resistance to standardized employee selection is, therefore, an important first step toward ensuring employment decisions are evidence based (Highhouse, 2008).

Power and politics are fundamental issues involved with evidence-based decision making (Hodgkinson, 2012;
Pettigrew, 1973; Pfeffer, 1981), and the idea that social science can be applied to the workplace in an apolitical and interest-free fashion is an untenable proposition (Hodgkinson, 2012; Johns, 1993). Recognizing the importance of these issues, Meehl (1986) suggested that a primary factor contributing to professionals' reluctance to adopt standardized decision-making practices is the "threat of technological unemployment" (p.374). Technological unemployment is a concept that can be traced back to the Luddite riots of early 19th-century Britain, a time when textile artisans protested the introduction of machinery that made it possible for them to be replaced with less-skilled laborers (Standing, 1984). Applied to decision making, the "threat of technological unemployment" argues that professional decision makers resist standardized decision-making practices because using these practices lessens the perceived value they provide to their employing organizations by reducing the extent to which the outcomes of decisions are attributed to their own expert judgment (Meehl, 1986).

\section{Corresponding author:}

Kevin P. Nolan, PhD

105D Hauser Hall, Hofstra University, Hempstead, NY 11542 Email: kevin.p.nolan@hofstra.edu 
Employee selection is fundamentally a sociopolitical process (Cleveland \& Murphy, 1992; Herriot, 1989), and this manuscript presents two studies that examine the tenability of Meehl's (1986) "threat of technological unemployment" explanation for why hiring professionals are reluctant to adopt standardized decision-making practices. Study 1 uses the tenets of attribution theory's discounting principle (Kelley, 1973) to argue that stakeholders attribute less credit to practitioners for the outcomes of employment decisions when structured rather than unstructured interviews are used to collect information about candidates and analytical rather than holistic data combination is used to determine candidates' overall evaluations. Study 2 then examines practitioners' own beliefs about the ways in which using the standardized employee selection practices affect the credit they receive for the outcomes of employment decisions and the extent to which these beliefs influence their intentions to use the hiring practices. If using employee selection practices that are designed to promote organizational interests adversely affects practitioners' own professional interests, then the effective implementation of these practices will require efforts to reconcile conflicting agendas.

\section{Decision Making for Employee Selection}

Employee selection is characterized by the data collection methods and data combination techniques that are used to make decisions (Gatewood, Feild, \& Barrick, 2010; Sawyer, 1966). Data collection methods refer to the ways in which practitioners gather information about candidates. Nonstandardized data collection methods, like unstructured interviews, primarily rely on human judgment to gather information about candidates, whereas standardized data collection methods, like structured interviews, curtail the influence of human judgment through uniform assessment formats and formal rating scales. Data combination techniques refer to the ways in which practitioners integrate information about candidates into overall evaluations that are ultimately used to make predictions. Nonstandardized data combination techniques, like intuition, primarily rely on human judgment to integrate information, whereas standardized data combination techniques, like linear models, minimize the influence of human judgment through statistical or mechanical procedures.

The creation of standardized employee selection practices that reduce error in prediction of employee performance is recognized as one of the greatest accomplishments of the organizational sciences. The inability to convince practitioners to use them, however, is arguably their greatest failure (Highhouse, 2008). Rynes (2012) reviewed the gaps between research and practice in industrial-organizational psychology, human resource management, and other related fields and concluded that, "One of the most widely documented and persistent of these gaps involves practi- tioner preferences for using intuitive methods of selection, particularly nonstandardized employment interviews, over standardized predictors and...mechanical combinations of selection techniques" (p.412). Of all the factors proposed to contribute to this divide, research suggests that stakeholders' perceptions of the employee selection process are among the most important.

In addition to their own personal beliefs about employee selection (Furnham, 2008; Nolan \& Highhouse, 2014), practitioners consider the beliefs of others who are stakeholders in the hiring process when determining the approaches used to make employment decisions (Ryan \& Ployhart, 2014). These stakeholders include current and future job candidates (König, Klehe, Berchtold, \& Kleinmann, 2010) as well as organizational colleagues and management (Terpstra \& Rozell, 1997; van der Zee et al., 2002). Generally, practitioners and candidates alike have great confidence in the use of human judgment for employee selection (Anderson, Salgado, \& Hulsheger, 2010; Diab, Pui, Yankelevich, \& Highhouse, 2011; Kohn \& Dipboye, 1998). Practitioners, for example, claim that nonstandardized employee selection practices allow them to (a) read between the lines and spot idiosyncrasies in candidates' profiles that make them inappropriate to hire (Jeanneret \& Silzer, 1998) and (b) interpret complex configurations of traits that are overlooked by simple linear models (Prien, Shippmann, \& Prien, 2003). Job candidates similarly report that nonstandardized employee selection practices are more useful and comprehensive than standardized alternatives (Diab et al., 2011; Kohn \& Dipboye, 1998; Latham \& Finnegan, 1993). The ways in which using standardized employee selection practices affect practitioners' reputations, however, are largely unknown.

Study 1 examines the effects using standardized employee selection practices have on stakeholders' beliefs about practitioners as professional decision makers. If stakeholders' beliefs are adversely affected by use of standardized practices, then the implementation of these practices presents a threat to the organizational value of hiring professionals. By examining the beliefs of stakeholders, the aim of Study 1 is to investigate the extent to which the "threat of technological unemployment" exists in the context of employee selection.

\section{STUDY 1}

Meehl (1986) suggested that using standardized decision-making practices reduces the perceived value professional decision makers provide to their employing organizations by lessening the extent to which their intuition is credited for the outcomes of decisions. This proposition is consistent with the tenets of attribution theory's discounting principle (Kelley, 1973). Attribution theory addresses 
the ways in which people explain events. Beliefs about the plausible causes for any given effect are referred to as a causal schema (Kelley \& Michela, 1980; Reeder \& Brewer, 1979). Causal schemas often include both internal and external factors. Internal factors refer to the personal attributes of an actor. External factors refer to aspects of the context in which the effect occurred (Kelley, 1973). For employee selection, human judgment is likely considered an internal factor because it resides within the practitioner, whereas standardized employee selection practices are likely considered external factors because they reside outside the practitioner as parts of the selection context. When a causal schema includes multiple sufficient causes, the discounting principle suggests that the presence of facilitative external factors (e.g., standardized practices) reduces the extent to which people attribute an outcome to internal factors (e.g., human judgment; Himmelfarb \& Anderson, 1975; Kelley \& Michela, 1980).

Research examining the use of standardized decision-making practices in the fields of medicine and accounting supports the tenets of attribution theory's discounting principle (Arkes, Shaffer, \& Medow, 2007; Lowe, Reckers, $\&$ Whitecotton, 2002). Pezzo and Pezzo (2006), for example, found that a physician who made a proper diagnosis using intuition was generally credited with a having made a higher quality decision than a physician who arrived at the same diagnosis using a standardized approach. In the case of misdiagnosis, however, the physician who relied on intuition was perceived as more negligent than the physician who used the standardized approach. Both findings are consistent with the discounting principle. The standardized decision-making practice reduced both the amount of credit and the amount of blame that was attributed to the professional for the accuracy of the diagnosis.

The structure of perceived causality includes three dimensions of attribution: locus of causality, personal control, and stability (Meyer \& Koelbl, 1982; Russell, 1982). Locus of causality (LOC) refers to the extent to which an observer perceives an outcome as having resulted from factors that are either internal or external to an actor (Russell, 1982; Weiner, 1985; 1986). This dimension of attribution is the focus of both the discounting principle and the "threat of technological unemployment." In accordance with these concepts, standardized employee selection practices are expected to reduce the extent to which the outcome of a hiring decision is attributed to the practitioner who made it. The "threat of technological unemployment" focuses on the loss of personal credit associated with favorable outcomes. However, consistent with the discounting principle, standardized employee selection practices are also expected to reduce the amount of blame practitioners receive for unfavorable outcomes.

Hypothesis 1a: Stakeholders' beliefs about locus of causality will be lower when the practitioner uses a struc- tured rather than an unstructured interview to collect information about candidates.

Hypothesis 1b: Stakeholders' beliefs about locus of causality will be lower when the practitioner uses a computer program rather than intuition to combine information about candidates into overall evaluations.

Personal control (PC) refers to the extent to which an actor is perceived as having been capable of changing an outcome had he/she tried (Russell, 1982; Weiner, 1985, 1986). Both the internal factors and external factors that make up a causal schema can vary in the extent to which they are perceived as controllable (Weiner, 1979, 1985). For example, with regard to internal factors, an actor may be perceived as having control over the level of effort he/ she exerts but no control over his/her ability or aptitude. With regard to external factors, an actor may be perceived to have control over the resources used to perform a task but no control over the difficulty of that task.

The amount of personal control practitioners experience during employee selection depends on the data collection methods and data combination techniques that are used to make decisions. Nonstandardized employee selection practices, like unstructured interviews and intuitive combination, typically provide practitioners with considerable control over the decision-making process. Practitioners are able determine which attributes to evaluate, how the attributes are evaluated, and the relative importance of attribute information (Dipboye, 1994; Highhouse \& Kostek, 2010; Huffcutt \& Arthur, 1994). Conversely, standardized employee selection practices are specifically designed to limit the influence practitioners have over the decision-making process (Gatewood et al., 2010; Meehl, 1954). Highly structured interviews, for example, require practitioners to ask the same questions in the same order to every candidate, questions are based on the results of formal job analyses, and specific rating scales are used to evaluate candidate responses (Campion, Pursell, \& Brown, 1988). Standardized data combination techniques similarly use mathematical formulae to integrate the same information in the same way across all candidates (Dawes, 1979). Because standardized practices impose more restrictions on practitioners than nonstandardized practices, stakeholders are expected to perceive those who use standardized practices as having less control over the hiring process than those who use nonstandardized alternatives.

Hypothesis 2a: Stakeholders' beliefs about personal control will be lower when the practitioner uses a structured rather than an unstructured interview to collect information about candidates.

Hypothesis 2b: Stakeholders' beliefs about personal control will be lower when the practitioner uses a computer program rather than intuition to combine information about candidates into overall evaluations. 
Stability refers to the perceived reliability of an outcome over time and across trials. Outcomes are perceived as stable when they result from causes that are constant and unstable when their causes are variable (Russell, 1982; Weiner, 1985; 1986). Standardized employee selection practices are more reliable than nonstandardized practices because they structure the decision-making process (Campion et al., 1988; Wiesner \& Cronshaw, 1988). Standardized data collection methods gather the same information in the same way across all candidates, and standardized data combination techniques integrate the same information in the same way across all candidates. Consequently, the decision-making process is consistent across people (both candidates and practitioners) and over time. Nonstandardized employee selection practices are considerably more variable. Across people, practitioners' idiosyncratic beliefs about employment have been shown to influence their behavior during unstructured interviews (Dougherty, Turban, \& Callender, 1994; Judge et al., 2000; Phillips \& Dipboye, 1989). Across time, research suggests that practitioners' moods affect their subjective evaluations of candidates (Baron, 1987). Because standardized employee selection practices structure the decision-making process, stakeholders are expected to perceive the outcome of a hiring decision as more stable when standardized rather than nonstandardized practices are used to make the decision.

Hypothesis 3a: Stakeholders'beliefs about stability will be greater when the practitioner uses a structured rather than an unstructured interview to collect information about candidates.

Hypothesis 3b: Stakeholders'beliefs about stability will be greater when the practitioner uses a computer program rather than intuition to combine information about candidates into overall evaluations.

\section{Study 1 Method}

\section{Participants}

Amazon's Mechanical Turk (MTurk) was used to recruit a sample of working Americans from over 35 occupations. MTurk is a crowdsourcing website that coordinates the supply and demand of tasks that require human intelligence (Buhrmester, Kwang, \& Gosling, 2011). Those who participated in the study were compensated $\$ .45$ for their effort. Participants who exhibited careless responding and/ or incorrectly responded to prompts embedded in the survey were removed from the data set. The final sample $(n=468)$ was primarily male $(62 \%)$ and Caucasian $(72 \%)$ with an average age of 28 years and average job tenure of 3 years. Descriptive statistics indicated that $16 \%$ of the sample had formal training in employee selection, $9 \%$ had formal training in human resource management, and $15.8 \%$ had jobs that require them to make employment decisions ${ }^{1}$.

\section{Design and Procedure}

Participants were randomly assigned to one condition of a 2 interview (standardized, nonstandardized) $\times 2$ combination (standardized, nonstandardized) $\times 3$ outcome (successful, unsuccessful, unknown) between-subjects design where they were presented with a hypothetical hiring scenario. Each scenario used the same introduction:

Imagine yourself in the following situation...The human resource (HR) manager at your company just hired a new employee to fill an open position. Please read the description of how this decision was made and answer the questions that follow.

However, descriptions of the manager's approach to hiring and the outcome of the employment decision varied according to the conditions of the study (see Table $1)$.

Participants assigned to the standardized and nonstandardized interview conditions reviewed employment interviews that were consistent with Levels 4 and 1, respectively, of Huffcutt and Arthur's (1994) taxonomy of interview question standardization. Participants assigned to the standardized data combination condition reviewed a selection system that uses a computer program to mathematically combine predictor information into overall candidate evaluations, whereas participants in the nonstandardized condition reviewed a system that relies on the decision maker to combine this information using intuition. The outcome of the hiring decision was manipulated by telling participants in the successful (unsuccessful) condition that, "After one year on the job, the employee who was hired using this approach was found to be a high (low) performer. In other words, the hiring decision was a success (failure)." Information about the outcome was absent from the unknown condition. After reviewing the scenarios, participants completed a brief survey that measured their causal attributions.

\section{Measures}

All measures used a 5-point Likert, $1=$ strongly disagree to $5=$ strongly agree, response scale.

Manipulation check. Two items assessed whether the presented approaches to employee selection were viewed as intended. These items are: "The interview portion of the hiring process seems very structured," and "The way interview scores were used to determine which candidate was hired was largely based on intuition."

Locus of causality. A three-item scale was developed to

\footnotetext{
1 Pearson $\chi^{2}$ tests were conducted to determine if the findings of this study were biased by overrepresentation of individuals with these experiences in any of the 12 experimental conditions. Nonsignificant results suggest that the distribution of these individuals was approximately uniform, with representation ranging from $11 \%$ to $26 \%$ per condition.
} 
TABLE 1.

\begin{tabular}{|c|c|c|c|}
\hline & \multicolumn{2}{|c|}{ Data collection method } \\
\hline & & Structured interview & Unstructured interview \\
\hline \multirow[t]{2}{*}{$\begin{array}{c}\text { Data } \\
\text { combination } \\
\text { technique }\end{array}$} & $\begin{array}{c}\text { Computer } \\
\text { program }\end{array}$ & $\begin{array}{l}\text { First, the HR manager used a standardized } \\
\text { interview to evaluate candidates. This interview } \\
\text { was designed by an employment specialist who } \\
\text { based the questions on the results of a formal } \\
\text { job analysis. The HR manager asked the same } \\
\text { interview questions in the same order to each } \\
\text { candidate. Candidates' responses to the ques- } \\
\text { tions were scored using specially designed } \\
\text { rating scales. After interviewing each candi- } \\
\text { date, the HR manager entered the scores into a } \\
\text { computer program. This program used a math- } \\
\text { ematical formula to calculate an overall score } \\
\text { for each candidate. The candidate who received } \\
\text { the highest overall score was the person who the } \\
\text { HR manager hired. }\end{array}$ & $\begin{array}{l}\text { First, the HR manager used personalized in- } \\
\text { terviews to evaluate candidates. The interviews } \\
\text { had no standardized format. The HR manager } \\
\text { asked each candidate a different set of questions } \\
\text { based on the candidate's own unique qualifica- } \\
\text { tions and experiences. The HR manager used } \\
\text { his/her own expert judgment to score the candi- } \\
\text { dates' responses to the interview questions. Af- } \\
\text { ter interviewing each candidate, the HR manag- } \\
\text { er entered the scores into a computer program. } \\
\text { This program used a mathematical formula to } \\
\text { calculate an overall score for each candidate. } \\
\text { The candidate who received the highest over- } \\
\text { all score was the person who the HR manager } \\
\text { hired. }\end{array}$ \\
\hline & Intuition & $\begin{array}{l}\text { First, the HR manager used a standardized } \\
\text { interview to evaluate candidates. This interview } \\
\text { was designed by an employment specialist who } \\
\text { based the questions on the results of a formal } \\
\text { job analysis. The HR manager asked the same } \\
\text { interview questions in the same order to each } \\
\text { candidate. Candidates' responses to the ques- } \\
\text { tions were scored using specially designed rat- } \\
\text { ing scales. After interviewing each candidate, } \\
\text { the HR manager entered the scores into a com- } \\
\text { puter spreadsheet. He/she reviewed these scores } \\
\text { and used his/her own personal intuition to de- } \\
\text { cide which candidate to hire. }\end{array}$ & $\begin{array}{l}\text { First, the HR manager used personalized } \\
\text { interviews to evaluate candidates. The inter- } \\
\text { views had no standardized format. The HR } \\
\text { manager asked each candidate a different set of } \\
\text { questions based on the candidate's own unique } \\
\text { qualifications and experiences. The HR manager } \\
\text { used his/her own expert judgment to score the } \\
\text { candidates' responses to the interview questions. } \\
\text { After interviewing each candidate, the HR man- } \\
\text { ager entered the scores into a computer spread- } \\
\text { sheet. He/she reviewed these scores and used } \\
\text { his/her own personal intuition to decide which } \\
\text { candidate to hire. }\end{array}$ \\
\hline
\end{tabular}

Note. Manipulation of the outcome factor is described in the Method section.

measure the extent to which the manager was perceived as the cause of the hiring outcome ( $\alpha=.82$; see Table 2$)$. An example item is, "The HR manager is responsible for the outcome of this hiring decision."

Personal control. A three-item scale was developed to measure the extent to which the manager was perceived as having control over the outcome of the hiring decision $(\alpha$ $=.88$ ). An example item is, "The HR manager had control over how the hiring decision was made."

Stability. A three-item scale was developed to measure the extent to which the cause of the hiring outcome was perceived as invariant over time $(\alpha=.78)$. An example item is, "Using this approach, the same candidate would always be hired regardless of the person who was making the hiring decision."

\section{Study 1 Results}

Although perceived causality is believed to have three unique dimensions of attribution (i.e., locus of causality, personal control, stability; Meyer \& Koelbl, 1982; Russell, 1982), results suggest that the scales used to measure these dimensions more appropriately fit a two-factor structure; with one factor measuring perceptions of causality/control and the other factor measuring perceptions of stability. Measures of locus of causality and personal control were highly related, $r=.76$. Results of confirmatory factor analyses suggests that a three-factor model showed acceptable fit $(\mathrm{RMSE}=.07$; SRMSR $=.06)$, but locus of causality and personal control had a very large interfactor correlation of .91. Further inspection and analysis also showed that substantive results were essentially identical for these two variables. Therefore, the three-item measures of locus of causality and personal control were combined into a sixitem scale measuring perceptions of causality/control, $\alpha=$ .91. Descriptive statistics and bivariate correlations among study measures are provided in Table 3.

Mean differences in the manipulation check items suggest that the standardized interview was perceived as more 
TABLE 2.

Attribution Measure Items: Locus of Causality, Personal Control, Stability

\section{Locus of Causality}

The HR manager is responsible for the outcome of this hiring decision.

The outcome of this hiring decision reflects the HR manager's ability to make hiring decisions.

You could attribute the outcome of this hiring decision to the HR manager.

\section{Personal control}

The HR manager had control over how the hiring decision was made.

The HR manager had the power to decide which candidate was hired.

The HR manager was able to change the hiring process as he/she saw fit.

\section{Stability}

If the same person evaluated the same candidate multiple times using this approach, the candidate's overall rating would be the same each time.

Using this approach, the same candidate would always be hired regardless of the person who was making the hiring decision.

If multiple people were using this approach to evaluate candidates, they would all agree on which candidate to hire.

structured $(M=4.31, S D=.82)$ than the nonstandardized interview $(M=2.73, S D=1.28), t_{(466)}=15.91, p<.01, d$ $=1.47$, and the standardized combination technique was perceived as less reliant on intuition $(M=2.47, S D=1.31)$ than the nonstandardized approach $(M=3.53, S D=1.22)$, $t_{(466)}=9.01, p<.01, d=.87$. Univariate ANOVAs were, therefore, conducted to examine the effects of standardizing the employee selection process on stakeholders' attributions. $^{2}$

Results suggest that both the type of interview used to evaluate candidates, $F_{(1,456)}=72.31, p<.01, \eta_{\text {partial }}^{2}=.14$, and the type of data combination technique used to form overall evaluations, $F_{(1,456)}=76.92, p<.01, \eta_{\text {partial }}^{2}=.15$, had significant main effects on stakeholders' perceptions of causality/control. These main effects, however, were superseded by a significant Interview $\times$ Combination interaction, $F_{(1,456)}=6.23, p=.01, \eta_{\text {partial }}^{2}=.01$ ( see Table 4 ). The HR manager was perceived to have the greatest causality/ control $(M=4.17, S D=.58)$ when the nonstandardized interview and nonstandardized approach to data combination were used together to make the employment decision and the least causality/control $(M=2.89, S D=1.02)$ when the standardized interview and standardized approach to data combination were used together to make the decision (see Figure 1). These results support hypotheses 1a, 1b, 2a, and $2 \mathrm{~b}$.

Results further suggest that both the type of interview used to evaluate candidates, $F_{(1,456)}=42.18, p<.01, \eta_{\text {partial }}^{2}$ $=.09$, and type of data combination technique used to form overall evaluations, $F_{(1,456)}=33.82, p<.01, \eta_{\text {partial }}^{2}=.07$, had significant main effects on stakeholders' perceptions of sta-

2 Hypotheses were tested twice, with and without controlling for participants' hiring experience. No substantive differences were found between the analyses. Due to the low base-rate of hiring experience among participants, the analyses conducted without controlling for hiring experience are reported.
TABLE 3.

Overall Descriptive Statistics and Bivariate Correlations Among Study 1 Measures

\begin{tabular}{lccccc}
\hline & $M(S D)$ & 1 & 2 & 3 & 4 \\
\hline 1. Locus of causality & $3.57(.95)$ & .82 & & & \\
2. Personal control & $3.68(1.02)$ & $.76^{*}$ & .88 & & \\
3. Stability & $2.88(1.01)$ & $-.41^{*}$ & $-.50^{*}$ & .78 & \\
4. Causality/control & $3.62(.92)$ & $.93^{*}$ & $.94^{*}$ & $-.49 *$ & .91 \\
\hline
\end{tabular}

Note: $* p<.05$; scale reliabilities on the diagonals.

bility. These main effects, however, were also superseded by a significant Interview $\times$ Combination interaction, $F_{(1,456)}$ $=4.79, p=.03, \eta_{\text {partial }}^{2}=.01$ (see Table 4). The outcome of the employment decision was perceived to be most stable $(M=3.51, S D=1.04)$ when the standardized interview and standardized approach to data combination were used together to make the decision and least stable $(M=2.45$, $S D=.87)$ when the nonstandardized interview and nonstandardized approach to data combination were used together to make this decision (see Figure 2). These results support Hypotheses $3 \mathrm{a}$ and $3 \mathrm{~b}$. Although a significant Combination $\times$ Outcome interaction was also found for causality/control, the magnitude of this effect is quite small, $\eta_{\text {partial }}^{2}=.01$, and no conclusions are drawn (Cortina \& Landis, 2009). ${ }^{3}$

\section{Discussion}

The results of Study 1 suggest that the "threat of technological unemployment" (Meehl, 1986) exists in the context of employee selection. Using the standardized em-

3 We note that the effect size for this interaction is equal to the Interview $\times$ Combination interactions that are discussed. The Interview $\times$ Combination interactions, however, provide meaningful qualification to observed main effects. There were no significant findings for the Outcome factor (Cortina \& Landis, 2009). 
TABLE 4.

ANOVAs for the Effect of Experimental Manipulations on Attribution Dimensions in Study 1

\begin{tabular}{|c|c|c|c|c|c|c|}
\hline Dependent variable & Factor & $M S$ & $F$ & $d f$ & $p$ & $\eta_{\text {partia }}^{2}$ \\
\hline \multirow[t]{9}{*}{ Causality/control } & Overall model & 9.53 & 14.94 & 11 & $<.001$ & .265 \\
\hline & Interview & 46.13 & 72.31 & 1 & $<.001$ & .137 \\
\hline & Combination & 49.07 & 76.92 & 1 & $<.001$ & .144 \\
\hline & Outcome & .21 & .33 & 2 & .722 & .001 \\
\hline & Interview $\times$ Combination & 3.97 & 6.23 & 1 & .013 & .013 \\
\hline & Interview $\times$ Outcome & .33 & .52 & 2 & .593 & .002 \\
\hline & Combination $\times$ Outcome & 1.96 & 3.07 & 2 & .047 & .013 \\
\hline & Interview $\times$ Combination $\times$ Outcome & .46 & .72 & 2 & .487 & .003 \\
\hline & Error & .64 & - & 456 & . & \\
\hline \multirow[t]{9}{*}{ Stability } & Overall model & 7.51 & 8.73 & 11 & $<.001$ & .174 \\
\hline & Interview & 36.32 & 42.18 & 1 & $<.001$ & .085 \\
\hline & Combination & 29.12 & 33.82 & 1 & $<.001$ & .069 \\
\hline & Outcome & 2.08 & 2.42 & 2 & .091 & .010 \\
\hline & Interview $\times$ Combination & 4.12 & 4.79 & 1 & .029 & .010 \\
\hline & Interview $\times$ Outcome & 1.08 & 1.25 & 2 & .288 & .005 \\
\hline & Combination $\times$ Outcome & 1.81 & 2.09 & 2 & .124 & .009 \\
\hline & Interview $\times$ Combination $\times$ Outcome & 1.83 & 2.13 & 2 & .120 & .009 \\
\hline & Error & .86 & . & 456 & . & \\
\hline
\end{tabular}

ployee selection practices was found to significantly reduce the extent to which stakeholders attributed the outcomes of employment decisions to the practitioners who were responsible for making them. Standardizing both the data collection (structured vs. unstructured interviews, $d=-.73$ ) and data combination (computer program vs. intuition, $d=-.74$ ) aspects of decision making had moderately large effects on stakeholders' beliefs about the practitioners' causality/control over the hiring process; with the type of interview used to evaluate candidates and the type of data combination technique used to determine candidates' overall evaluations accounting for approximately $12 \%$ and $13 \%$ of the variance observed in these perceptions, respectively. Stakeholders did, however, perceive the hiring process as moderately more stable (i.e., reliable) when the standardized rather than nonstandardized practices were used to collect $(d=.57)$ and combine $(d=.50)$ information about candidates; with the type of interview used to evaluate candidates and the

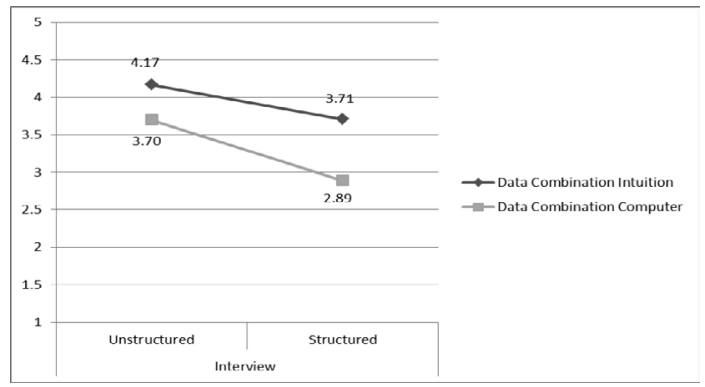

FIGURE 1. Mean Perceptions of Causality/Control Across Study 1 Conditions type of data combination technique used to determine candidates' overall evaluations accounting for approximately $8 \%$ and $6 \%$ of the variance observed in these perceptions, respectively.

By demonstrating the adverse effects using standardized employee selection practices have on the credit practitioners receive for the outcomes of employment decisions, Study 1 establishes that "threat of technological unemployment" exists in employee selection. The extent to which this threat is recognized by practitioners and it influences their use of employee selection practices, however, are unknown. Study 2 was, therefore, conducted to (a) examine the ways in which using standardized employee selection practices affect practitioners' beliefs about stakeholder attributions and (b) investigate the extent to which these beliefs influence practitioners' intentions to use the standardized practices to make employment decisions.

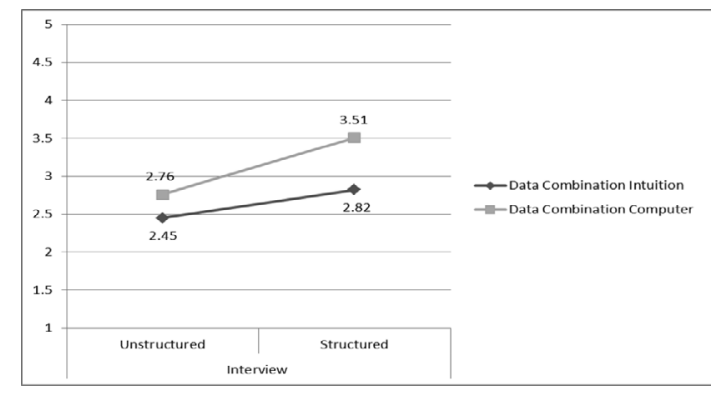

FIGURE 2. Mean Perceptions of Stability Across Study 1 Conditions 


\section{STUDY 2}

In order for the "threat of technological unemployment" (Meehl, 1986) to be a factor that influences practitioners' use of employee selection practices, practitioners must first recognize that they would receive less credit for the outcomes of employment decisions if standardized rather than nonstandardized practices were used to make those decisions. As such, this explanation for why practitioners resist standardized decision-making practices involves an element of perspective taking. Perspective taking refers to the cognitive capacity to consider the world from another individual's viewpoint (Galinsky, Maddux, Gilin, \& White, 2008). It is an important social competency that allows us to see ourselves and our situations through the eyes of others (Batson, Early, \& Salvarani, 1997). The cognitive structures that are formed through perspective taking are influenced by observations as well as prior knowledge and experience (Davis, Conklin, Smith, \& Luce, 1996). Practitioners who engage in perspective taking are, therefore, likely to consider their own experiences observing the hiring decisions of others when forming beliefs about the ways in which stakeholders perceive their own hiring practices. The results of Study 1 provide insight concerning the ways in which observers' causal attributions are affected by use of standardized employee selection practices. Consistent with these findings, practitioners are expected to believe that their own use of employee selection practices would affect stakeholders' causal attributions in the following ways.

Hypothesis 1a: Practitioners' beliefs about stakeholders' perceptions of their causality/control over the hiring process will be lower when the structured rather than unstructured interview is used to collect information about candidates.

Hypothesis 1b: Practitioners' beliefs about stakeholders' perceptions of their causality/control over the hiring process will be lower when a computer program rather than intuition is used to combine information about candidates into overall evaluations.

Hypothesis 2a: Practitioners' beliefs about stakeholders' perceptions of stability in the hiring process will be greater when the structured rather than unstructured interview is used to collect information about candidates.

Hypothesis 2b: Practitioners' beliefs about stakeholders' perceptions of stability in the hiring process will be greater when a computer program rather than intuition is used to combine information about candidates into overall evaluations.

Entertaining the psychological perspectives of others facilitates the development of interpersonal relationships by providing insight as to how behavior may be tailored to meet others' expectations (Davis, et al., 1996; Galper, 1976; Regan \& Totten, 1975). Accordingly, the "threat of tech- nological unemployment" posits that professional decision makers' resistance to standardized decision-making practices is an attempt to align their behavior with the expectations of others with whom they do not want to jeopardize the nature of their professional relationships. Research strongly supports the notion that perspective taking plays an important role in shaping behavior (Davis et al., 1996; Galinsky et al., 2008). Studies employing the theory of planned behavior (Ajzen, 1991), for example, have repeatedly demonstrated that behavioral intentions are influenced by normative beliefs concerning the likelihood that important individuals or groups approve of the behaviors (i.e., subjective norms). In the context of employee selection, research likewise suggests that practitioners' use of employee selection practices is meaningfully influenced by their beliefs about the ways in which the practices are viewed by others who are stakeholders in the hiring process (König, Klehe, Berchtold, \& Kleinmann 2010; Ryan \& Ployhart, 2014; Terpstra \& Rozell, 1997). Van der Zee et al. (2002), for example, found that practitioners' intentions to use structured and unstructured interviews were significantly influenced by theirs concerns about coworkers' approval of the practices.

As an explanation for why practitioners resist standardized employee selection practices, the "threat of technological unemployment" suggests that practitioners' behavior is motivated by their beliefs about stakeholders' causal attributions. More specifically, practitioners' beliefs about the amount of credit they will receive from stakeholders for the outcomes of employment decisions is posited to influence their intentions to use employee selection practices via concerns about the perceived value of their employment. In addition to the informal consequences loss of credit may have on practitioners' power and political status within their organizations, more formal consequences may be experienced by practitioners who work for employers that practice strategic compensation. Strategic compensation programs base the relative worth of employees on the value provided by their individual competencies and the extent to which their work contributes to organizational success (Bohlander \& Snell, 2010). If using standardized employee selection practices reduces the extent to which practitioners' judgment is credited for the outcomes of successful hiring decisions, then the value of this specific competency to organizations is likely to decrease as well. Consistent with the "threat of technological unemployment" explanation (Meehl, 1986), the relationship between practitioners' beliefs about stakeholders' perceptions of their causality/control over the hiring process and their intentions to use the employee selection practices is, therefore, expected to be partially mediated by concerns about the perceived value of their employment.

Hypothesis 3: Practitioners' concerns about technological unemployment will partially mediate the relationship between their beliefs about stakeholders' perceptions of 
their causality/control over the hiring process and their intentions to use the employee selection practices.

Regarding practitioners' beliefs about stakeholders' perceptions of stability in the hiring process, research suggests that people generally hold favorable attitudes toward hiring practices that are consistent and administered without bias (Hausknect, Day, \& Thomas, 2004; Ryan \& Ployhart, 2000). Via perspective taking, practitioners are likely to recognize stakeholders' favorable attitudes toward stability and desire to align their behavior accordingly. Therefore, practitioners' beliefs about stakeholders' perceptions of stability in the hiring process are expected to have a positive influence on their intentions to use employee selection practices.

Hypothesis 4: Practitioners' intentions to use the employee selection practices will be positively influenced by their beliefs about stakeholders' perceptions of stability in the hiring process.

\section{Study 2 Method}

\section{Participants}

MTurk was again used to recruit a sample of working Americans from over 35 occupations. Those who completed the survey were compensated $\$ .50$ for their effort. Participants who exhibited careless responding and/or failed to correctly answer the prompts embedded in the survey were removed from the data set. Likewise, participants who reported having no experience with employee selection were also removed from the data set. The final sample $(n$ $=150)$ was primarily female $(56 \%)$ and Caucasian $(77 \%)$ with an average age of 36 years and average job tenure of 6 years. Descriptive statistics suggest that $84 \%$ of the sample completed some form of education beyond a high school degree (e.g., trade/vocational degree, bachelor's degree) and that $70 \%$ of participants were currently in a position with direct reports (e.g., supervisor, manager). Although all participants indicated having experience with employee selection, only $35 \%$ reported receiving formal training on the subject. Participants reported having the most experience reviewing/evaluating application materials and conducting unstructured interviews, and the least experience administering/reviewing the results of personality inventories and intelligence tests (see Table 5).

\section{Design and Procedure}

Participants were randomly assigned to one condition of a 2 interview (standardized, nonstandardized) $\times 2 \mathrm{com}$ bination (standardized, nonstandardized) between-subjects factorial design where they were presented with a hypothetical hiring scenario. Each scenario used the same introduction:

Image yourself in the following situation... Your company has given you permission to hire an assistant. They have also offered a recommendation for how to identify the best candidate for the job. You are free, however, to make this hiring decision in any way that you see fit. Please read a description of the approach recommended by your organization and tell us what you think about using it.

Descriptions of the approach offered by the organization, however, varied according to study conditions in ways that were commensurate with Study 1 (see Table 6).

\section{Measures}

Manipulation check. The manipulation check items from Study 1 were again used to assess if the presented approaches to employee selection were viewed as intended.

Attributions. The six-item causality/control measure $(\alpha$ $=.93)$ and the three-item stability measure $(\alpha=.71)$ from

TABLE 5.

Attribution Measure Items: Locus of Causality, Personal Control, Stability

\begin{tabular}{lcc}
\hline Concerning your experience evaluating job candidates and making hiring decisions, how often have you... \\
\hline & $M$ & $S D$ \\
\hline reviewed/evaluated application materials & 4.09 & 1.21 \\
conducted unstructured employment interviews & 3.70 & 1.67 \\
performed reference checks & 3.42 & 1.74 \\
conducted structured employment interviews & 3.30 & 1.78 \\
reviewed/evaluated samples of work behavior (e.g., simulations) & 3.29 & 1.80 \\
reviewed/evaluated profiles posted on social networking websites (e.g., LinkedIn) & 3.21 & 1.72 \\
administered or reviewed the results of personality inventories & 2.89 & 1.80 \\
administered or reviewed the results of intelligence tests & 2.52 & 1.80 \\
been the person who is ultimately responsible for making a hiring decision & 2.36 & .77 \\
\hline
\end{tabular}

*Note: responses made using the following scale: $1=$ never, $2=$ a few times, $3=$ somewhat often, $4=$ often, $5=$ very often 
TABLE 6.

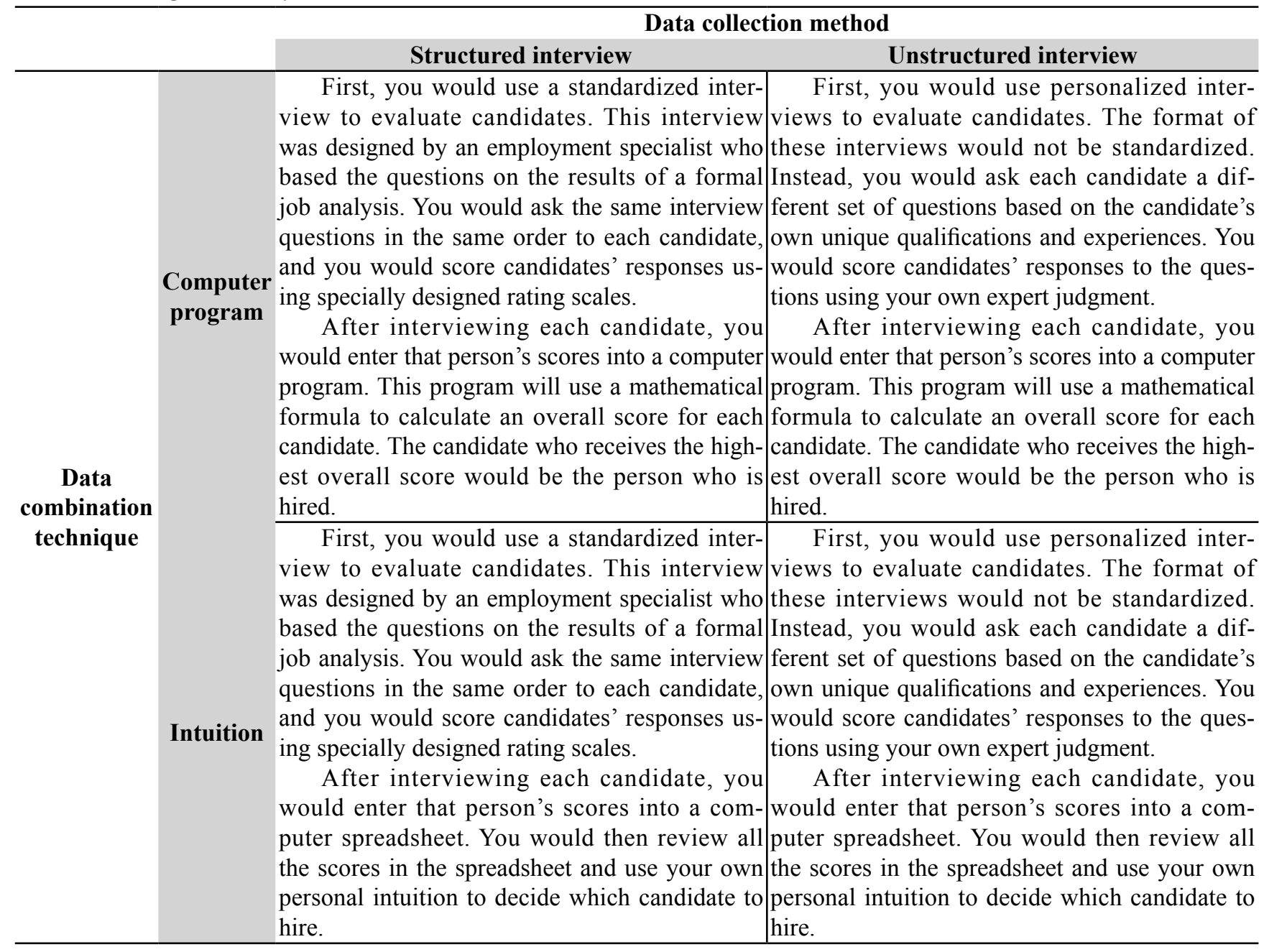

Study 1 were modified and used to evaluate attributions in Study 2. For example, the item from Study 1 reading, "The HR manager is responsible for the outcome of this hiring decision" was modified to read, "Others in the organization who knew the process used to make this hiring decision would consider me responsible for the outcome of the decision."

Use intentions. A modified version of the three-item scale from Nolan and Highhouse (2014) was used to measure use intentions $(\alpha=.88)$. An example item from this scale is, "I would use this approach to make the hiring decision."

Threat of technological unemployment. A five-item scale was developed to measure beliefs about the extent to which the approaches to employee selection pose a threat to one's employment status $(\alpha=.93$; see Table 7). An example item from this scale is, "Consistently using this approach to make hiring decisions would lessen others' beliefs about the value I provide to my employing organization."

\section{Study 2 Results}

Descriptive statistics and bivariate correlations among study measures are provided in Table 7. Mean differences in the manipulation check items suggest that the standardized interview was perceived as more structured, $M=4.40$, $S D=.69$, than the nonstandardized interview, $M=3.17, S D$ $=1.32, t_{(148)}=7.23, p<.01, d=1.19$, and the standardized combination techniques was perceived as less reliant on intuition, $M=2.82, S D=1.38$, than the nonstandardized approach, $M=3.85, S D=1.00, t_{(148)}=5.23, p<.01, d=.86$. Univariate ANOVAs were, therefore conducted to examine the effects of standardizing the selection process on practitioners' beliefs about stakeholder attributions.

Results suggest that both the type of interview used to evaluate candidates, $F_{(1,146)}=8.34, p<.01, \eta_{\text {partial }}^{2}=.06$, and the type of data combination technique used to form overall evaluations, $F_{(1,146)}=30.53, p<.01, \eta_{\text {partial }}^{2}=.17$, had significant main effects on practitioners' beliefs about stakeholders' perceptions of their causality/control over the hiring 
TABLE 7.

Threat of Technological Unemployment Measure

Consistently using this approach to make hiring decisions would...

undermine my usefulness as an employee.

reduce the perceived importance of my position within the company.

lessen others' beliefs about the value I provide to my employing organization.

diminish my professional reputation.

threaten the status of my employment with the organization.

process (see Table 8 and Figure 3). These findings provide support for Hypotheses $1 \mathrm{a}$ and $1 \mathrm{~b}$.

Results further suggest that the type of interview used to evaluate candidates had a significant main effect on practitioners' beliefs about stakeholders' perceptions of stability in the hiring process, $F_{(1,146)}=7.03, p<.01, \eta_{\text {partial }}^{2}=.05$. This main effect, however, was superseded by a significant Interview $\times$ Combination interaction, $F_{(1,146)}=3.97,{ }_{\mathrm{p}}<.05$, $\eta_{\text {partial }}^{2}=.03$ (see Table 9). Practitioners believed that stakeholders would perceive the outcome of the employment decision as being most stable when the standardized interview was partnered with the standardized data combination technique (see Figure 4). These results provide support for Hypotheses 2a and $2 b$.

To test the mediated relationship posited in Hypothesis 3, path analysis was conducted using the R package "lavaan" (Rosseel, 2012) with 1,000 bootstrapped samples for estimation of standard errors and associated confidence intervals. The findings reported are from the standardized solution and are shown in Figure 5. Results suggest that practitioners' beliefs about stakeholders' perceptions of their causality/control over the hiring process had a large negative influence on the perceived threat of technological unemployment, $b=-.40, S E=.09, p<.01$, which in turn had a large negative influence on the practitioners' intentions to use the employee selection practices to make employment decisions, $b=-.45, S E=.08, p<.01$. Consistent with the partial mediation hypothesis, the direct influence of beliefs regarding causality/control on use intentions remained significant while controlling for the perceived threat of technological unemployment, $b=.20, S E=.09, p=.02$. The predictors explained $27.80 \%$ of the variance in use intentions, and the indirect effect was also significant, $b=$ $.18, S E=.06, p<.01$, with a bias-corrected and accelerated (BCa) confidence interval ranging from .08 to .30 , just under half of the total effect, $b=.38, S E=.09, p<.01$. These findings support Meehl's (1986) "threat of technological unemployment" explanation for why practitioners resist standardized decision-making practices.

Hypothesis 4 was tested by examining the bivariate correlation between practitioners' beliefs about stakeholders' perceptions of stability in the hiring process and their intentions to use the employee selection practices. Results
TABLE 8.

Overall Descriptive Statistics and Bivariate Correlations Among Study 2 Measures

\begin{tabular}{lccccc}
\hline & $M(S D)$ & 1 & 2 & 3 & 4 \\
\hline 1. Locus of causality & $3.50(.96)$ & .93 & & & \\
2. Personal control & $3.11(.89)$ & $-.26^{*}$ & .71 & & \\
3. Stability & $3.00(.98)$ & $-.39^{*}$ & .06 & .93 & \\
4. Causality/control & $2.65(1.03)$ & $.35^{*}$ & $.24^{*}$ & $-.50^{*}$ & $.87^{*}$ \\
\hline
\end{tabular}

Note: $* p<.05$; scale reliabilities on the diagonals.

indicate a significant positive relationship between practitioners' beliefs about stakeholders' perceptions of stability and their use intentions, $r=.24, p<.01$ (see Table 8). These results provide support for the hypothesis.

\section{Discussion}

The results of Study 2 further support the tenability of Meehl's (1986) "threat of technological unemployment" explanation for why practitioners of employee selection resist standardized decision-making practices. Practitioners were generally aware of the effects using standardized employee selection practices have on stakeholder attributions. Consistent with the ways in which the standardized practices were found to actually affect stakeholder attributions in Study 1, the results of Study 2 suggest that practitioners believed stakeholders would perceive them as having less causality/control over the hiring process and that the hiring process would be perceived as more stable when the standardized rather than nonstandardized practices were used to make employment decisions.

Standardizing the data collection method (structured v. unstructured interviews, $d=-.46$ ) had a modest effect on practitioners' beliefs about stakeholders' perceptions of their causality/control over the hiring process; with the type of interview used to evaluate candidates accounting for approximately $5 \%$ of the variance observed in these beliefs. Standardizing the data combination technique (computer program v. intuition, $d=-.90$ ), however, had a much greater effect on practitioners' beliefs about stakeholders' perceptions of causality/control, with the type of technique used to determine candidates' overall evaluations accounting 
TABLE 9.

ANOVAs for the Effect of Experimental Manipulations on Attribution Dimensions in Study 2

\begin{tabular}{|c|c|c|c|c|c|c|}
\hline Dependent variable & Factor & $M S$ & $F$ & $d f$ & $p$ & $\eta_{\text {partia }}^{2}$ \\
\hline \multirow[t]{5}{*}{ Causality/control } & Overall model & 9.78 & 13.43 & 3 & $<.001$ & .216 \\
\hline & Interview & 6.08 & 8.34 & 1 & .004 & .055 \\
\hline & Combination & 22.28 & 30.53 & 1 & $<.001$ & .173 \\
\hline & Interview $\times$ Combination & .17 & .24 & 1 & .627 & .002 \\
\hline & Error & .73 & . & 146 & . & \\
\hline \multirow[t]{5}{*}{ Stability } & Overall model & 3.58 & 4.93 & 3 & .003 & .092 \\
\hline & Interview & 5.11 & 7.03 & 1 & .009 & .046 \\
\hline & Combination & 2.18 & 3.00 & 1 & .086 & .020 \\
\hline & Interview $\times$ Combination & 2.88 & 3.97 & 1 & .048 & .026 \\
\hline & Error & .73 & . & 146 & & \\
\hline
\end{tabular}

for approximately $16 \%$ of the variance observed in these beliefs. Regarding practitioners' beliefs about stakeholders' perceptions of stability in the hiring process, results suggest that standardizing both the data collection (structured v. unstructured interviews, $d=.44$ ) and data combination (computer program v. intuition, $d=.30$ ) aspects of decision making had modest effects on these beliefs; with the type of interview used to evaluate candidates and the type of data combination technique used to determine candidates' overall evaluations accounting for approximately $4 \%$ and $2 \%$ of the variance observed, respectively.

The "threat of technological unemployment" posits that the reason why professional decision makers resist standardized decision-making practices is because they believe that using these practices will lessen the perceived value they provide to their employing organizations by reducing the extent to which the outcomes of decisions are attributed to their own expert judgment (Meehl, 1986). In support of the explanatory mechanism linking stakeholder attributions and use intentions, the results of Study 2 suggest that the relationship between practitioners' beliefs about stakeholders' perceptions of their causality/control over the hiring process and their intentions to use the employee selection practices was partially mediated by concerns about the perceived value of their employment. As practitioners' beliefs about stakeholders' perceptions of their causality/control over

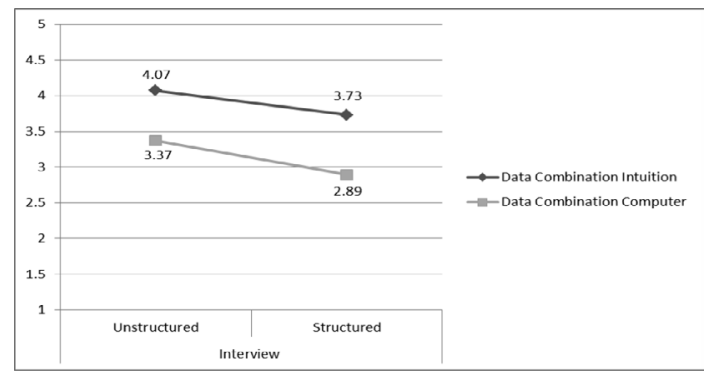

FIGURE 3. Mean Perceptions of Causality/Control Across Study 2 Conditions the hiring process decreased with use of the standardized employee selection practices, concerns about the perceived value of their employment increased, which subsequently decreased their intentions to use the practices to make employment decisions. This finding supports the proposition that "threat of technological unemployment" (Meehl, 1986) is an important factor influencing practitioners' use of hiring practices (Grove \& Meehl, 1996).

Practitioners' intentions to use the employee selection practices were also significantly influenced by their beliefs about the extents to which stakeholders would perceive the hiring process as stable (i.e., reliable). Perceived stability was found to have a positive influence on practitioners' use intentions. This finding is consistent with research on applicant reactions, which suggests that people generally hold favorable attitudes toward employee selection practices that are perceived as consistent and free from bias (Hausknect et al., 2004).

\section{General Discussion}

Organizational researchers have conducted thousands of studies dedicated to identifying fair and valid employee selection practices (Cascio \& Aguinis, 2008). This body of research strongly supports the use of standardized data collection methods, like structured interviews, that uniformly

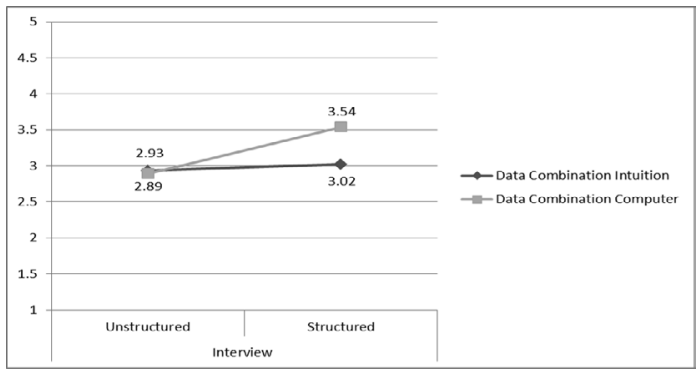

FIGURE 4. Mean Perceptions of Stability Across Study 2 Conditions 


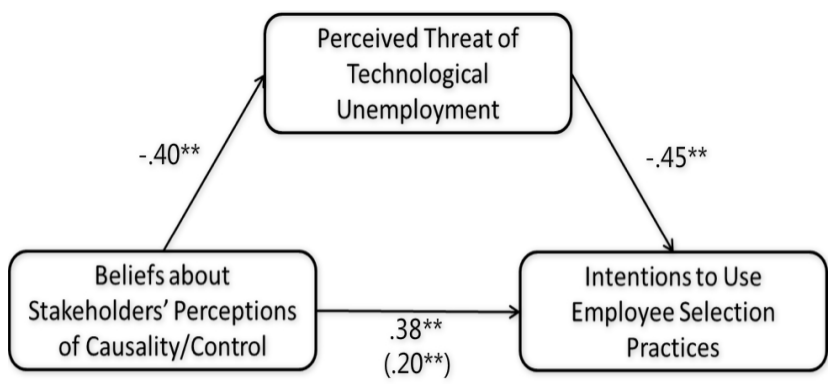

FIGURE 5. Partially Mediated Relationship Among Study 2 Variables.

Note. ${ }^{* *} p<.01 ; * p<.05$

gather information about candidates (McDaniel, Whetzel, Schmidt, \& Mauer, 1994; Schmidt \& Hunter, 1998) and standardized data combination techniques, like mathematical formulae, that integrate information analytically to create overall applicant evaluations (Borman, 1982; Highhouse \& Kostek, 2010; Tziner \& Dolan, 1982; Wollowick \& McNamara, 1969). Practitioners, nevertheless, continue to prefer unstructured and intuition-based approaches to hiring that compromise the reliability and predictive validity of employee selection systems by exposing the hiring process to the idiosyncratic beliefs and biases of decision makers (Arthur et al., 2006; Conway et al., 1995; Ryan et al., 1999; Simola et al., 2007). In order to better understand the factors that influence practitioners' resistance to standardized employee selection practices, two studies were conducted that examine the tenability of Meehl's (1986) "threat of technological unemployment" explanation, which posits that professional decision makers resist standardized decision-making practices because they believe that using these practices will lessen the perceived value they provide to their employing organizations by reducing the extent to which the outcomes of decisions are attributed to their own expert judgment.

The results of Study 1 suggest that the "threat of technological unemployment" exists in the context of employee selection. Stakeholders were found to attribute less credit to practitioners for the outcomes of employment decisions when structured rather than unstructured interviews were used to evaluate candidates and analytical rather than holistic data combination was used to determine candidates' overall evaluations. These findings are consistent with attribution theory's discounting principle (Kelley, 1973), which suggests that the presence of facilitative external factors (e.g., standardized decision-making practices) in a causal schema tends to reduce the extent to which people attribute an outcome to internal factors (e.g., human judgment). Stakeholders, however, perceived the hiring process as significantly more stable when the standardized rather than nonstandardized employee selection practices were used to make employment decisions.
Whereas the results of Study 1 suggest that "threat of technological unemployment" exists in the context of employee selection, the results of Study 2 suggest that this threat is an important factor influencing practitioners' resistance to standardized employee selection practices. Practitioners generally recognized the effects using the standardized practices have on stakeholders' perceptions of their causality/control over the hiring process as well as their perceptions of stability. Furthermore, practitioners' beliefs about stakeholder attributions were found to significantly influence their intentions to use the employee selection practices to make employment decisions. Consistent with the explanation offered by the "threat of technological unemployment," as practitioners' beliefs about stakeholders' perceptions of their causality/control over the hiring process decreased with use of the standardized employee selection practices, concerns about the perceived value of their employment increased, which subsequently decreased their intentions to use the practices to make employment decisions. Practitioners' beliefs about stakeholders' perceptions of stability in the hiring process, however, had a moderate positive influence on their intentions to use the employee selection practices.

Together, the results of Study 1 and Study 2 suggest that practitioners' use of employee selection practices is meaningfully influenced by their beliefs about the role of expert judgment in the decision-making process. "Expert judgment" has been previously identified as an important factor influencing practitioners' resistance to standardized hiring practices. Highhouse (2008), for example, suggested that practitioners prefer to use judgment rather than standardized employee selection practices because they believe that judgment results in more accurate predictions. The explanation offered by the "threat of technological unemployment" for why beliefs about expert judgment influence employee selection, however, is quite different. Whereas previous explanations posit that practitioners' use of employee selection practices is motivated by their desire to do what is best for organizations (i.e., hire candidates with the greatest likelihoods of success), the explanation offered by the "threat of technological unemployment" posits that practitioners' use of employee selection practices is motivated by their desire to do what is best for their own careers-maintain/enhance the perceived value of their expert judgment. These explanations for why practitioners resist standardized employee selection practices are respectively attuned with the "do good" and "look good" motives of impression management theory (Bolino, 1999; Grant \& Mayer, 2009).

Lewin (1951) suggested that change only occurs in organizations when the forces that promote change outweigh the forces that maintain status quo. Together, these studies identify the "threat of technological unemployment" as a force working to maintain status quo in employee selection 
(i.e., practitioners' continued preference for nonstandardized employee selection practices). The results of this research, however, also identify several factors that may be leveraged to promote organizational change in the form of adopting more standardized employee selection practices. Study 1, for example, found that in addition to reducing the amount of credit practitioners received for the outcomes of successful employment decisions, using the standardized employee selection practices also reduced the amount of blame practitioners received for the outcomes of unsuccessful employment decisions. Standardized employee selection practices are typically promoted by communicating the gains in predictive validity these practices provide over their nonstandardized counterparts. A more persuasive argument, however, might be made by also communicating the potential losses associated with not using the standardized practices. Research, for example, suggests that psychological pain associated with losses is approximately twice as great as the psychological pleasure associated with gains and that people are more willing to take risks when options are presented in terms of potential losses rather than potential gains (Kahneman \& Tversky, 1979; Hastie \& Dawes, 2001; Kuhberger, Schulte-Mecklenbeck, \& Perner, 1999). Increasing practitioners' awareness of the culpability associated with nonstandardized employee selection practices and framing their use in terms of potential losses may prove an effective strategy for motivating the adoption of more standardized approaches to hiring.

The results of this research further suggest that perceptions of stability in the hiring process are a force that may be leveraged to promote change in employee selection. Stakeholders perceived the hiring process as significantly more stable when the standardized rather than nonstandardized practices were used to make employment decisions, and practitioners' beliefs about stakeholders' perceptions of stability were found to have a positive influence on their intentions to use employee selection practices. Emphasizing the perceived stability of standardized employee selection practices and reminding practitioners that stakeholders generally hold favorable attitudes toward hiring practices that are consistent and administered without bias (Hausknecht et al., 2004) might prove a useful strategy for promoting the adoption of more standardized approaches to employee selection.

\section{Limitations and Future Directions}

There are several limitations to this research that should be acknowledged. First, inferences about the effects using standardized employee selection practices have on stakeholder attributions, and the extent to which practitioners' beliefs about stakeholder attributions influence their use of employee selection practices, are limited to the specific data collection and data combination techniques included in this research. Future research is needed to understand how using other standardized employee selection practices (e.g., cognitive ability tests, personality inventories) affects, and is affected by, stakeholder attributions. Likewise, future research is need to understand how "threat of technological unemployment" is affected by the design of employee selection systems. Systems that include multiple data collection methods and multiple data combination techniques (e.g., judgmental composite, mechanical synthesis; Bass \& Barrett, 1981; Gatewood, Feild, \& Barrick, 2010) would likely alter the magnitude of the observed effects.

In the context of employee selection, the "threat of technological unemployment" derives from the perceptions of those who are stakeholders in the hiring process. Stakeholders were operationalized as employees working for the same organization as the practitioner in Study 1 and others in the organization who know about the hiring process in Study 2 . There are a variety of stakeholders, however, both internal (e.g., future coworkers, managers) and external (e.g., current and future job candidates) to the organization, who are invested in the hiring process for various reasons. Future research is needed to understand differences in the way practitioners' experience "threat of technological unemployment" from stakeholders in these various positions.

Last, this research was conducted using hypothetical hiring scenarios with samples of American workers recruited via Amazon's Mechanical Turk. Although this methodology is useful for establishing proof of concept (i.e., does this effect even exist?) in the early stages of research, future research should employ methodologies that identify boundary conditions of the effect (Zhu, Barnes-Farrell, \& Dalal, 2015). Longitudinal field studies that examine the ways in which stakeholders' beliefs about practitioners are affected by use of standardized and nonstandardized employee selection practices over time and across organizations, for example, would provide a more in-depth understanding of the extent to which the "threat of technological unemployment" influences decision making for employee selection.

Although this research provides initial support for the notion that practitioners' resistance to standardized employee selection practices is influenced by concerns about the extent to which using the practices lessens the perceived value of their expert judgment, future research is needed to more fully understand why standardization adversely affects beliefs about practitioners' causality/control over the hiring process. This effect may result from the reduced latitude practitioners experience during the data collection and data combination aspects of decision making, it may result from using employee selection practices that others (e.g., HR managers, hiring specialists) have worked to create, or it may result from a combination of these as well as other factors. A more complete understanding of why standardization threatens the perceived value of practitioners would aid in developing structured approaches to employee selection 
that are less threatening. For example, if using standardized employee selection practices reduces the credit stakeholders attribute to practitioners' expert judgment because these practices are developed by employment specialists, then it may be possible to reduce the "threat of technological unemployment" by involving practitioners' expert judgment in creation of the practices (e.g., allowing practitioners to decide which interview questions they will use to evaluate candidates from a list of structured interview questions designed to assess job-related attributes). Researchers are encouraged to build upon the findings of this study by further investigating the ways in which the "threat of technological unemployment" affects, and is affected by, the use of standardized employee selection practices.

Identifying the factors that underlie practitioners' resistance to standardized employee selection practices is an important first step toward ensuring employment decisions are evidence-based (Highhouse, 2008). Organizational researchers who are interested in promoting the use of best-practices are encouraged to examine the cultural (e.g., Boatman \& Erker, 2012), organizational (e.g., Wilk \& Cappellik, 2003), and personal (e.g., Nolan \& Highhouse, 2014) attributes that influence decision making for employee selection. Likewise, additional insight may be provided by exploring issues related to judgment and decision making in other fields - especially those like medicine (e.g., Giluk \& Rynes, 2012), auditing (e.g., Lowe, et al., 2002), and law (e.g., Eastwood, Snook, \& Luther, 2012)—that are also experiencing difficulty convincing professionals to use the standardized practices that have been developed to aid decision making. Once the factors underlying practitioners' resistance to standardized hiring practices have been identified, this information can then be used to help organizational research design and implement employee selection systems that are more attractive to practitioners yet retain the predictive validity and legal defensibility of traditional standardized approaches (Kuncel, 2008).

\section{CONCLUSIONS}

Research investigating the factors that influence use of employee selection practices has primarily focused on people's (e.g., applicants, practitioners) beliefs about the specific data collection methods and data combination techniques that are used to make decisions. By shifting the focus away from people's beliefs about employee selection practices and onto people's beliefs about the practitioners that use them, this study furthers our understanding of what motivates practitioners' reluctance to adopt standardized hiring practices. Results suggest that practitioners' continued use of nonstandardized practices, despite the current state of academic research, may not be the result of an irrational decision-making process driven purely by hubris (i.e., unfounded faith in "expert" intuition; Highhouse, 2008) but rather the result of a decision-making process wherein consequences concerning both the quality of hiring outcomes and practitioners' own political interests are considered. Differences in the goals of multiple stakeholders must not be treated like minor byproducts of an otherwise radical improvement to organizational decision making. Instead, the effective implementation of standardized employee selection practices will likely require systematic efforts to reconcile conflicting agendas (Hodgkinson, 2012).

\section{REFERENCES}

Ajzen, I. (1991). The theory of planned behavior. Organizational Behavior and Human Decision Processes, 50, 179-211.

Anderson, N., Salgado, J. F., \& Hulsheger, U. R. (2010). Applicant reactions in selection: Comprehensive metaanalysis into reaction generalization versus situational specificity. International Journal of Selection and Assessment, 18, 291-304.

Arkes, H. R., Shaffer, V. A., \& Medow, M. A. (2007). Patients derogate physicians who use a computer-assisted diagnostic aid. Medical Decision Making, 27, 189-202.

Arthur Jr., W. A., Bell, S. T., Villado, A. J., \& Doverspike, D. (2006). The use of person-organization fit in employment decision making: An assessment of its criterion-related validity. Journal of Applied Psychology, 91, 786-801.

Baron, R. A. (1987). Interviewer's moods and reactions to job applicants: The influence of affective states on applied social judgments. Journal of Applied Social Psychology, 17, 911-926.

Bass, B. M., \& Barrett, G. V. (1981). People, work, and organizations, 2nd ed. Boston: Allyn \& Bacon, 392.

Batson, D., Early, S., \& Salvarani, G. (1997). Perspective taking: Imagining how another feels versus imagining how you would feel. Personality and Social Psychology Bulletin, 23, 751-758.

Boatman, J., \& Erker, S. (2012). Global selection forecast: Know more. guess less. Pittsburg, PA: Developmental Dimensions International.

Bohlander, G., \& Snell, S. (2010). Managing human resources. Mason, $\mathrm{OH}$ : South-Western Cengage Learning.

Bolino, M. C. (1999). Citizenship and impression management: Good soldiers or good actors? Academy of Management Review, 24, 82-98.

Borman, W. C. (1982). Validity of behavioral assessment for predicting military recruiter performance. Journal of Applied Psychology, 67, 3-9.

Buhrmester, M., Kwang, T., \& Gosling, S. D. (2011). Amazon's Mechanical Turk: A new source of inexpensive, yet high-quality, data? Perspectives on Psychological Science, 6, 3-5.

Cascio, W. F., \& Aguinis, H. (2008). Research in industrial and organizational psychology from 1963 to 2007: Changes, choices, and trends. Journal of Applied 
Psychology, 93, 1062- 1081.

Campion, M. A., Pursell, E. D., \& Brown, B. K. (1988). Structured interviewing: Raising the psychometric properties of the employment interview. Personnel Psychology, 41, 25-42.

Cleveland, J. N., \& Murphy, K. R. (1992). Analyzing performance appraisal as a goal directed behavior. Research in Personnel and Human Resource Management, 10, 121-185.

Conway, J. M., Jako, R. A., \& Goodman, D. F. (1995). A meta-analysis of interrater and internal consistency reliability of selection interviews. Journal of Applied Psychology, 80, 565-579.

Cortina, J. M., \& Landis, R. S. (2009). When small effect sizes tell a big story, and when large effect sizes don't. In C. E Lance, \& R. J. Vandenberg, (Eds.), Statistical and methodological myths and urban legends: Doctrine, verity and fable in organizational and social sciences, (pp. 287-308). New York, NY: Routledge/Taylor \& Francis Group.

Davis, M. H., Conklin, L., Smith, A., \& Luce, C. (1996). Effect of perspective taking on the cognitive representation of persons: A merging of self and other. Journal of Personality and Social Psychology, 70, 713-726.

Dawes, R. M. (1979). The robust beauty of improper linear models in decision making. American Psychologist, 34, 571-582.

Diab, D. L., Pui, S., Yankelevich, M., \& Highhouse, S. (2011). Lay perceptions of selection decision aids in U.S. and non-U.S. samples. International Journal of Selection and Assessment, 19(2), 209-216.

Dipboye, R. L. (1994). Structured and unstructured selection interviews: Beyond the job-fit model. In G. Ferris (Ed.), Research in personnel and human resources management (Vol. 12, pp. 79-123). Greenwich, CT: JAI Press.

Dougherty, T. W., Turban, D. B., \& Callender, J. C. (1994). Confirming first impressions in the employment interview: A field study of interviewer behavior. Journal of Applied Psychology, 79, 659-665.

Eastwood, J., Snook, B., \& Luther, K. (2012). What people want from their professionals: Attitudes toward decision-making strategies. Journal of Behavioral Decision Making, 25, 458-468.

Furnham, A. (2008). HR professionals' beliefs about and knowledge of, assessment techniques and psychometric tests. International Journal of Selection and Assessment, 16, 300-305.

Galinsky, A. D., Maddux, W. M., Gilin, D., \& White, J. B. (2008). Why it pays to get inside the head of your opponent: The differential effects of perspective taking and empathy in negotiations. Psychological Science, 19, 378-384.

Galper, R. E. (1976). Turning observers into actors: Differential causal attributions as a function of "empathy." Journal of Research in Personality, 10, 328335.

Gatewood, R. D., Feild, H. S., \& Barrick, M. (2010). Human resource selection. Cengage Learning.
Giluk, T. L., \& Rynes S. (2012). Research findings practitioners resist: Lessons for management academics from evidence-based medicine. In D. M. Rousseau, (Ed.), The Oxford handbook of evidence-based management (pp. 130-164). New York, NY: Oxford University Press.

Grant, A. M., \& Mayer, D. M. (2009). Good soldiers and good actors: Prosocial and impression management motives as interactive predictors of affiliative citizenship behaviors. Journal of Applied Psychology, 94, 900-912.

Grove, W. M., \& Meehl, P. E. (1996). Comparative efficiency of informal (subjective, impressionistic) and formal (mechanical, algorithmic) prediction procedures: The clinical-statistical controversy. Psychology, Public Policy, and Law, 2, 293-323.

Hastie, R., \& Dawes, R. M. (2001). Rational choice in an uncertain world: The psychology of judgment and decision making. Thousand Oaks, CA: Sage.

Hausknecht, J.P., Day, D.V., \& Thomas, S.C. (2004). Applicant reactions to selection procedures: An updated model and meta-analysis. Personnel Psychology, 57, 639-683.

Herriot, P. (1989). Selection as a social process. In M. Smith and I. T. Robertson (Eds.), Advances in Selection and Assessment (pp. 171-87). New York: Wiley.

Highhouse, S. (2008). Stubborn reliance on intuition and subjectivity in employee selection. Industrial and Organizational Psychology, 1, 333-342.

Highhouse, S., \& Kostek, J.A. (2010). Holistic assessment for selection and placement. In K. F. Geisinger, B. A. Bracken, J. F. Carlson, J-I. C. Hansen, N. R. Kuncel, S. P. Reise, M. C. Rodriguez, (Eds.), APA Handbook of Testing and Assessment in Psychology. Vol. 1: Test theory and testing and assessment in industrial and organizational psychology (pp. 565-577). Washington, DC: American Psychological Association.

Himmelfarb, S., \& Anderson, N.H. (1975). Integration-theory applied to opinion attribution. Journal of Personality and Social Psychology, 31, 1064-1071.

Hodgkinson, G. P. (2012). The politics of evidence-based decision making. In D. M. Rousseau, (Ed.), The Oxford Handbook of Evidence-Based Management, (pp. 404419). New York, NY: Oxford University Press.

Huffcutt, A. I., \& Arthur, W., Jr. (1994). Hunter and Hunter (1984) revisited: Interview validity for entry-level jobs. Journal of Applied Psychology, 79, 184-190.

Jeanneret, R., \& Silzer, R. (1998). An overview of psychological assessment. In R. Jeanneret \& R. Silzer (Eds.), Individual psychological assessment: Predicting behavior in organizational settings (pp. 3-26). San Francisco, CA: Jossey-Bass.

Johns, G. (1993). Constraints on the adoption of psychology-based personnel practices: Lessons from organizational innovation. Personnel Psychology, 46, 569-592.

Judge, T. A., Higgins, C. A., \& Cable, D. M. (2000). The employment interview: A review of recent research and recommendations for future research. Human Resource Management Review, 10, 383-406. 
Kahneman, D., \& Tversky, A. (1979). Prospect theory: An analysis of decision under risk. Econometrica: Journal of the Econometric Society, 47, 263-292.

Kelley, H. H. (1973). The process of causal attribution. American Psychologist, 28, 107-128.

Kelley, H. H., \& Michela, J. L. (1980). Attribution theory and research. Annual Review of Psychology, 31, 457-501.

Kohn, L. S., \& Dipboye, R. L. (1998). The effects of interview structure on recruiting outcomes. Journal of Applied Social Psychology, 28, 821-843.

König, C.J., Klehe, U., Berchtold, M., \& Kleinmann, M. (2010). Reasons for being selective when choosing personnel selection procedures. International Journal of Selection and Assessment, 18, 17-27.

Kuhberger, A., Schulte-Mecklenbeck, M., \& Perner, J. (1999). The effects of framing, reflection, probability, and payoff on risk preference in choice tasks. Organizational Behavior and Human Decision Processes, 78, 204-231.

Kuncel, N. (2008). Some new (and old) suggestions for improving personnel selection. Industrial and Organizational Psychology, 1, 343-346.

Latham, G. P., \& Finnegan, B. J. (1993). Perceived practicality of unstructured, patterned, and situational interviews. In H. Schuler, J. L. Farr, \& M. Smith, (Eds.), Personnel selection and assessment: Individual and organizational perspectives, (pp. 41-55). Mahwah, NJ: Erlbaum.

Lewin, K. (1951). Field theory in social science. New York, NY: Harper \& Brothers.

Lowe, D. J., Reckers, P. M. J., \& Whitecotton, S. M. (2002). The effects of decision-aid use and reliability on juror's evaluations of auditor liability. The Accounting Review, 77, 185-202.

McDaniel, M. A., Whetzel, D. L., Schmidt, F. L., \& Maurer, S. (1994). The validity of employment interviews: A comprehensive review and meta-analysis. Journal of Applied Psychology, 79, 599-616.

Meehl, P. E. (1954). Clinical versus statistical prediction. Minneapolis, MN: University of Minnesota Press.

Meehl, P.E. (1986). Causes and effects of my disturbing little book. Journal of Personality Assessment, 50, 370-375.

Meyer, J. P., \& Koelbl, S. L. M. (1982). Dimensionality of students' causal attributions for test performance. Personality and Social Psychology Bulletin, 8, 31-36.

Nolan, K. P., \& Highhouse, S. (2014). Need for autonomy and resistance to standardized employee selection practices. Human Performance, 27, 328-346.

Pettigrew, A. M. (1973). The Politics of Organizational Decision Making. London, UK: Tavistock.

Pezzo, M. V., \& Pezzo, S. P. (2006). Physician evaluation after medical errors: Does having a computer decision aid help or hurt in hindsight? Medical Decision Making, 26, 48-56.

Pfeffer, J. (1981). Power in organizations. Boston, MA: Pitman.

Phillips, A. P., \& Dipboye, R. L. (1989). Correlational tests of predictions form a process model of the interview. Journal of Applied Psychology, 74, 41-52.

Prien, E. P., Shippmann, J. S., \& Prien, K. O. (2003).
Individual assessment: As practiced in industry and consulting. Mahwah, NJ: Erlbaum.

Reeder, G. D., \& Brewer, M. B. (1979). A schematic model of dispositional attribution in interpersonal perception. Psychological Review, 86, 61-79.

Regan, D. T., \& Totten, J. (1975). Empathy and attribution: Turning observers into actors. Journal of Personality and Social Psychology, 32, 850-856.

Rosseel, Y. (2012). lavaan: An R Package for Structural Equation Modeling. Journal of Statistical Software, 48, 1-36.

Russell, D. (1982). The causal dimension scale: A measure of how individuals perceive causes. Journal of Personality and Social Psychology, 42, 1137-1145.

Ryan, A. M., McFarland, L., Baron, H., \& Page, R. (1999). An international look at selection practices: Nation and culture as explanations for variability in practice. Personnel Psychology, 52, 359-391.

Ryan, A. M., \& Ployhart, R. E. (2000). Applicants' perceptions of selection procedures and decisions: A critical review and agenda for the future. Journal of Management, 26, 565-606.

Ryan, A. M., \& Ployhart, R. E. (2014). A century of selection. Annual Review of Psychology, 65, 693-717.

Rynes, S. L. (2012). The research-practice gap in industrial/organizational psychology and related fields: Challenges and potential solutions. In S. W. J. Kozlowski (Ed.), The Oxford Handbook of IndustrialOrganizational Psychology (pp. 409-452). New York, NY: Oxford University Press.

Sawyer, J. (1966). Measurement and prediction, clinical and statistical. Psychological Bulletin, 66, 178.

Schmidt, F. L., \& Hunter, J. E. (1998). The validity and utility of selection methods in personnel psychology: Practical and theoretical implications of 85 years of research findings. Psychological Bulletin, 124, 262-274.

Simola, S. K., Taggar, S., \& Smith, G. W. (2007). The employment selection interview: Disparity among research-based recommendations, current practices and what matters to human rights tribunals. Canadian Journal of Administrative Sciences, 24, 30-44.

Standing, G. (1984). The notion of technological unemployment. International Labor Review, 123, 127 147.

Terpstra, D. E., \& Rozell, E. J. (1997). Why some potentially effective staffing practices are seldom used. Public Personnel Management, 26, 483-495.

Tziner, A., \& Dolan, S. (1982). Validity of an assessment center for identifying future female officers in the military. Journal of Applied Psychology, 67, 728-736.

van der Zee, K. I., Bakker, A. B., \& Bakker, P. (2002). Why are structured interviews so rarely used in personnel selection? Journal of Applied Psychology, 87, 176-184.

Weiner, B. (1979). A theory of motivation for some classroom experiences. Journal of Educational Psychology, 71, 3-25.

Weiner, B. (1985). "Spontaneous" causal search. Psychological Bulletin, 97, 74-84.

Weiner, B. (1986). An attributional theory of motivation and 
emotion. New York, NY: Springer-Veriag.

Wiesner, W. H., \& Cronshaw, S.F. (1988). A meta-analytic investigation of the impact of interview format and degree of structure on the validity of the employment interview. Journal of Occupational and Organizational Psychology, 61, 275-290.

Wilk, S. L., \& Cappelli, P. (2003). Understanding the determinants of employer use of selection methods. Personnel Psychology, 56, 103-124.

Wollowick, H. B., \& McNamara, W. J. (1969). Relationship of the components of an assessment center to management success. Journal of Applied Psychology, 53, 348-352.

Zhu, X., Barnes-Farrell, J. L., \& Dalal, D. K. (2015). Stop apologizing for your samples, start embracing them. Industrial and Organizational Psychology, 8, 228-232.

RECEIVED 4/29/15 ACCEPTED 6/23/16 